\title{
Body Weight Concerns among Urban Adolescent Girls: A Microlevel Study
}

\author{
Susmita Mukhopadhyay, ${ }^{1}$ Nandini Ganguly, ${ }^{1}$ and Shailendra Kumar Mishra ${ }^{2}$ \\ ${ }^{1}$ Biological Anthropology Unit, Indian Statistical Institute, 203 Barrackpore Trunk Road, Kolkata 700108, India \\ ${ }^{2}$ Department of Anthropology, University of Allahabad, Allahabad 211002, India
}

Correspondence should be addressed to Shailendra Kumar Mishra; shailendra17@gmail.com

Received 29 March 2014; Revised 15 June 2014; Accepted 15 June 2014; Published 2 July 2014

Academic Editor: Kaushik Bose

Copyright (c) 2014 Susmita Mukhopadhyay et al. This is an open access article distributed under the Creative Commons Attribution License, which permits unrestricted use, distribution, and reproduction in any medium, provided the original work is properly cited.

\begin{abstract}
Growing consciousness about ideal body image leads to dietary modifications and consequent eating disorders among girls in developing countries like India. The present study aims to (i) assess the prevalence of body weight consciousness and related behaviours among a group of adolescent girls; (ii) assess the sociodemographic correlates of weight related behaviours; and (iii) compare weight related behaviours of the girls of two religious groups residing in Howrah. The study is the outcome of a crosssectional school based survey involving 280 (159 Hindu and 121 Muslim) girls from standards 8 to 11. Significant differences exist between two religious groups with respect to their family size, socioeconomic profile, and media exposures (in terms of watching television). Consciousness about body weight among girls shows significant difference with respect to religion, family size $\left(\chi^{2}=64.77\right)$, father's occupation $\left(\chi^{2}=60.28\right)$, level of education of both the parents, and media exposure $(P<0.05)$. Consciousness about body weight drives them to adopt several behavioural measures like calorie restriction, food avoidance, and dieting. Sociodemographic correlates of all these behaviours have been analyzed. The study documents that concern over body image and weight loss is quite important among these urban girls.
\end{abstract}

\section{Introduction}

Consciousness over body image and losing weight has become very common among adolescent girls. Modernized societies prefer thinness and socially discriminate against obese individuals. Incidence of obesity is also on the rise as a result of excessive consumption of processed foods, high fat diets, and less exercise $[1,2]$.

Dietary pattern of a population group is generally governed by its socioeconomic and cultural characteristics along with their exposure to outside world [3]. Weight related conditions like disordered eating behaviours adversely affect the growth process, psychosocial development, and physical health of young people [4]. Thus, unhealthy eating habits among adolescents pose serious public health concerns [5]. Dissatisfaction over body image followed by unhealthy eating habits and attitudes may be a risk factor for the development of eating disorders such as anorexia nervosa and bulimia nervosa [6]. Both these disorders are common among adolescents, who often remain confused regarding what constitutes overweight, normal weight, and underweight. Body image dissatisfaction and a desire to be thinner are two most important motivating factors for dieting among majority of teenagers [7].

Driven by the feeling of dissatisfaction over body image, adolescents practice dietary modifications and/or dieting, which usually refer to changes in the food preferences and amount of consumption and also can help increase or decrease body fat [7].

Dieting is a poorly defined behaviour having various meanings to patients and professionals. Overall, it stands for an intentional, often temporary, change in eating to achieve weight loss [7-9]. Chronic dieting (more than 10 diets in a year), fad dieting, fasting, and skipping meals are also considered as unhealthy strategies [10, 11]. Many authors have described these behaviours as disordered eating if the behaviours are not sufficiently severe to warrant a diagnosis of an eating disorder $[12,13]$.

Eating disorders are characterized by abnormal eating habits and involve either excessive or insufficient food intake, 
which eventually become detrimental to both physical and psychological health.

A study by Chugh and Puri [14], among teenage girls of Delhi, India, have reported that approximately fifty percent of the girls presently are on a diet which could easily be called as "starvation diet," leading to various nutrient deficiencies, hormonal imbalance, and sometimes amenorrhoea (cessation of menstruation). Another study by Sadana et al. [15] showed that 73.3 and $78.4 \%$ of urban adolescent girls consumed fast foods between meals, hence, reducing appetite for regular meals. A healthy adolescent Indian girl usually consumes four meals a day, two major meals and two snacks.

Studies across the globe have identified that several factors such as age, gender, economic status, perceived media, and peer pressure are important in determining eating behaviours and weight concern among adolescents $[2,16$, 17]. The objectives of the present study are (i) to assess the prevalence of body weight consciousness and related behaviours; (ii) to assess the sociodemographic correlates of weight related behaviours; and (iii) to compare weight related behaviours of girls belonging to two different religious groups residing in the same city.

\section{Materials and Methods}

2.1. Study Population and Design. The study participants are all residents of Howrah city, belonging to two different religious groups-Hindu (159) and Muslim (121). They differ in socioeconomic status. Howrah is situated between $22.59^{\circ} \mathrm{N}$ and $88.31^{\circ} \mathrm{E}$ and is the second largest industrial city in West Bengal with a population around 1.5 lakhs [18]. The climate condition of the area is typically tropical. The study participants include adolescent girls aged 13-19 years, who were students of 8 th to 11th (having completed eight years and eleven years of formal schooling, resp.) standards from three high schools and two Madrasahs. Madrasahs are educational institutions to impart education to Muslims. In West Bengal full convergence has been established between the schools and the Madrasahs in respect to discrimination from schools to Madrasahs and vice versa [19]. In eastern India including West Bengal rice is the staple food and is taken during major meals. Their usual meal patterns include tea, biscuit, puffed rice, and bread as breakfast and boiled rice, vegetables, and one nonvegetarian item (usually fish) as lunch. For snacks and refreshments they prefer puffed rice, noodles, small cakes, and other fast foods. Dinner usually include wheat bread (roti) and vegetables. In general, beef and pork are considered as religious taboo by Hindus and Muslims, respectively. Food types and consumption pattern depends generally on the geoclimatic conditions of the region and socioeconomic status of the household. It is assumed that the difference in religion will not affect the food habit in a major way since the study participants belong to one cultural zone. Unlike many other parts of the country, both Hindus and Muslims consume nonvegetarian diets regularly and their major food items as well as consumption pattern is almost similar in this region.

The study essentially was cross-sectional in nature with a sample size of 280 adolescent girls. The study participants were selected from the schools in which school authorities consented to cooperate (3 High schools and 2 Madrasahs). Further, girls from 8th to 11th standard were selected owing to the girls as well as their parents' consent to participate in the study. The study participants were interviewed in the school premises during the months of August-September 2009 and information was collected with the help of standard questionnaires.

\subsection{Data Types}

2.2.1. Sociodemographic Characteristics. It includes age, religion, family size, that is, number of household members, parents' level of education and occupation, and possible influence of media. Study participants were divided into three age groups (13 years, 14 to 16 , and $\geq 17$ years). For family size three categories were made ( $\leq 3$ members, 4 to 6 members, and $\geq 7$ members). Socioeconomic characteristics of these study participants were ascertained in terms of occupation of father and education of both the parents. Many of the girls were not able to provide information on their monthly family income; therefore, it has not been considered as independent variable for analysis. Father's occupations were divided into three categories, that is, skilled and nonskilled works, business, and service. Mother's and father's level of education was divided into three categories, that is, below 10 years, $10-12$ years, and more than 12 years of formal education.

2.2.2. General Eating/Dieting Behaviour. In the absence of cross-culturally tested questionnaire to investigate eating and dieting behaviours of Indian adolescents, Eating Attitude Test (EAT) questionnaire [20] was used. EAT is a widely used 40item self-administered questionnaire that measures symptoms and concerns that characterises eating disorders. However, it is not designed to diagnose the disorder but can be used as a first step in the screening process and also as a useful tool for assessing eating disorder risks. Scoring is done using a 4-point scale, where higher score indicates greater risks.

2.3. Data Analysis. Chi-square statistics was used to estimate the levels of differences obtained in sociodemographic characteristics while comparing the girls of two religious groups. From EAT questionnaire, to begin with questions were grouped together with their relevance to the issues related to risky dietary practices such as dieting, that is, conscious reduction in food intake along with skipping major meals, concern of being overweight and calorie consumption; food avoidance, that is, conscious avoidance of certain food items. For each issue a group score was calculated based on study participant's answers to these questions. The questions used to calculate score for one issue have not been repeated to calculate score for other issues. To test the internal consistency of the questionnaire and inter-item reliability Cronbach's alpha was calculated. The value of Cronbach's alpha had been greater than 0.8. Owing to ordinal nature of variables, that is, issues related to risky dietary practices; Mann-Whitney $U$-test was used to compare mean group scores of Hindu and Muslim girls for sociodemographic variables considered in the present study. Further, stepwise linear regressions were carried out considering dieting, food avoidance, 
TABLE 1: Sociodemographic profile of the study participants.

\begin{tabular}{|c|c|c|c|c|}
\hline Variables & $\begin{array}{c}\text { Hindu } \\
(n=159)\end{array}$ & $\begin{array}{c}\text { Muslim } \\
(n=121)\end{array}$ & $\chi^{2}$-value & $\begin{array}{c}\text { Total } \\
(n=280)\end{array}$ \\
\hline \multicolumn{5}{|l|}{ Age group } \\
\hline$\leq 13$ years & $34(21.38)$ & $19(15.70)$ & \multirow{3}{*}{4.76} & $53(18.93)$ \\
\hline $14-16$ years & $96(60.38)$ & $88(72.73)$ & & $184(65.71)$ \\
\hline$\geq 17$ years & $29(18.24)$ & $14(11.57)$ & & $43(15.36)$ \\
\hline \multicolumn{5}{|l|}{ Family size } \\
\hline$\leq 3$ members & $49(30.82)$ & $1(0.83)$ & \multirow{3}{*}{$64.77^{* *}$} & $50(17.86)$ \\
\hline $4-6$ members & $97(61.01)$ & $73(60.33)$ & & $170(60.71)$ \\
\hline$\geq 7$ members & $13(8.18)$ & $47(38.84)$ & & $60(21.43)$ \\
\hline \multicolumn{5}{|l|}{ Socioeconomic characteristics } \\
\hline \multicolumn{5}{|l|}{ Father's occupation } \\
\hline Skilled and nonskilled workers & $10(6.29)$ & $40(33.06)$ & \multirow[t]{3}{*}{$60.28^{* *}$} & $50(17.86)$ \\
\hline Business & $59(37.11)$ & $62(51.24)$ & & $121(43.21)$ \\
\hline Service & $90(56.60)$ & $19(15.70)$ & & $109(38.93)$ \\
\hline \multicolumn{5}{|l|}{ Father's level of education } \\
\hline Below 10 years & $27(16.98)$ & $82(67.77)$ & \multirow{3}{*}{$78.02^{* *}$} & $109(38.93)$ \\
\hline $10-12$ years & $65(40.88)$ & $27(22.31)$ & & $92(32.86)$ \\
\hline More than 12 years & $67(42.14)$ & $12(9.92)$ & & $79(28.21)$ \\
\hline \multicolumn{5}{|l|}{ Mother's level of education } \\
\hline Below 10 years & $35(22.01)$ & $93(76.86)$ & \multirow{3}{*}{$86.49^{* *}$} & $128(45.71)$ \\
\hline $10-12$ years & $84(52.83)$ & $25(20.66)$ & & $109(38.93)$ \\
\hline More than 12 years & $40(25.16)$ & $3(2.48)$ & & $43(15.36)$ \\
\hline \multicolumn{5}{|l|}{ Influence of media } \\
\hline \multicolumn{5}{|l|}{ Exposure to television } \\
\hline Yes & $143(89.94)$ & $52(42.98)$ & $71.68^{* *}$ & $195(69.64)$ \\
\hline \multicolumn{5}{|l|}{ Exposure to newspapers } \\
\hline Yes & $77(48.43)$ & $24(19.83)$ & $24.36^{* *}$ & $101(36.07)$ \\
\hline \multicolumn{5}{|l|}{ Exposure to magazines } \\
\hline Yes & $109(68.55)$ & $29(23.97)$ & $54.65^{* *}$ & 138 (49.29) \\
\hline
\end{tabular}

${ }^{*}$ Significant at 0.05 level; ${ }^{* *}$ significant at 0.01 level.

consciousness about calorie intake, and concern for being overweight as dependent variables, whereas sociodemographic factors as independent variables.

\section{Results}

It is observed from Table 1 that Muslims show significant difference with respect to sociodemographic variables like family size, level of education, and type of occupation of both the parents. Among the Muslims level of education of maximum fathers $(67.7 \%)$ and mothers (76.9\%) are below 10 years, while maximum number of Hindu fathers (40.8\%) and mothers $(52.8 \%)$ have attained 10 to 12 years of education. As for type of occupation of fathers, Hindus are mostly engaged in service $(56.6 \%)$, while Muslims are engaged in business (51.2\%). For For Hindus $8.18 \%$ of mothers reported to have some earning of their own as against only $0.83 \%$ of Muslim mothers who earn (not shown in table). In the absence of data on household income these variables were considered as proxy for economic status. It is noticed that Muslim girls are lagging behind Hindu girls with respect to watching television (42.9\% against $89.9 \%)$ and in reading newspapers (19.8\% against $46.4 \%)$ and magazines $(23.9 \%$ against $68.5 \%$ ) and all the differences are statistically significant.

Table 2 depicts concern over consciousness on body weight (being overweight) and size and behaviours related to it. Significant difference is noticed with respect to family size, father's level of education and occupation, and the level of exposure to television, between the Hindu and Muslim girls.

The study further reveals that religion, economic status, level of parental education, and media influence are shown to 
TABLE 2: Descriptive statistics of weight related behaviours among the study participants and results of Kruskal-Wallis test and Mann-Whitney tests for certain sociodemographic correlates.

\begin{tabular}{|c|c|c|c|c|}
\hline \multirow[t]{2}{*}{ Variable } & Dieting & Food avoidance & $\begin{array}{l}\text { Consciousness about } \\
\text { calorie intake }\end{array}$ & $\begin{array}{c}\text { Concern about being } \\
\text { overweight }\end{array}$ \\
\hline & Mean $( \pm$ SD $)$ & Mean $( \pm \mathrm{SD})$ & Mean $( \pm S D)$ & Mean $( \pm$ SD $)$ \\
\hline \multicolumn{5}{|l|}{ Age group } \\
\hline$\leq 13$ years & $2.45 \pm 0.77^{*}$ & $1.56 \pm 0.76$ & $1.77 \pm 1.12^{*}$ & $1.57 \pm 1.51$ \\
\hline $14-16$ years & $2.73 \pm 0.94$ & $1.74 \pm 0.98$ & $1.94 \pm 1.36$ & $1.60 \pm 1.32$ \\
\hline$\geq 17$ years & $2.84 \pm 0.87$ & $1.76 \pm 0.80$ & $2.07 \pm 1.44$ & $1.81 \pm 1.56$ \\
\hline \multicolumn{5}{|l|}{ Religion } \\
\hline Hindu & $2.90 \pm 0.91^{* *}$ & $1.80 \pm 0.69$ & $2.06 \pm 1.45^{*}$ & $1.93 \pm 1.45^{* *}$ \\
\hline Muslim & $2.54 \pm 0.86$ & $1.66 \pm 0.93$ & $1.75 \pm 1.14$ & $1.19 \pm 1.42$ \\
\hline \multicolumn{5}{|l|}{ Family size } \\
\hline$\leq 3$ members & $2.67 \pm 0.91$ & $1.75 \pm 0.84$ & $2.28 \pm 1.44^{*}$ & $1.82 \pm 1.41^{*}$ \\
\hline 4-6 members & $2.85 \pm 0.79$ & $1.70 \pm 0.89$ & $1.92 \pm 1.32$ & $1.71 \pm 1.52$ \\
\hline$\geq 7$ members & $2.60 \pm 1.01$ & $1.67 \pm 0.81$ & $1.67 \pm 0.82$ & $1.17 \pm 1.37$ \\
\hline \multicolumn{5}{|l|}{$\begin{array}{l}\text { Socioeconomic } \\
\text { characteristics }\end{array}$} \\
\hline \multicolumn{5}{|l|}{ Father's occupation } \\
\hline $\begin{array}{l}\text { Skill and nonskilled } \\
\text { work }\end{array}$ & $2.51 \pm 0.82^{* *}$ & $1.56 \pm 0.88^{*}$ & $1.68 \pm 0.96$ & $1.20 \pm 1.26^{*}$ \\
\hline Business & $2.74 \pm 0.89$ & $1.76 \pm 0.10$ & $1.94 \pm 1.52$ & $1.55 \pm 1.54$ \\
\hline Service & $2.98 \pm 1.02$ & $1.85 \pm 0.83$ & $2.03 \pm 1.24$ & $1.86 \pm 1.47$ \\
\hline \multicolumn{5}{|l|}{$\begin{array}{l}\text { Father's Level of } \\
\text { education }\end{array}$} \\
\hline Below 10 years & $2.52 \pm 0.86^{* *}$ & $1.53 \pm 0.90^{*}$ & $1.71 \pm 1.09^{*}$ & $1.17 \pm 1.25^{* *}$ \\
\hline $10-12$ years & $2.62 \pm 0.88$ & $1.79 \pm 0.79$ & $1.95 \pm 1.48$ & $1.61 \pm 1.51$ \\
\hline Above 12 years & $2.89 \pm 0.94$ & $1.80 \pm 0.82$ & $2.22 \pm 1.40$ & $2.23 \pm 1.54$ \\
\hline \multicolumn{5}{|l|}{$\begin{array}{l}\text { Mother's Level of } \\
\text { education }\end{array}$} \\
\hline Below 10 years & $2.44 \pm 0.73^{* *}$ & $1.58 \pm 0.91$ & $1.72 \pm 1.14$ & $1.15 \pm 1.27^{* *}$ \\
\hline $10-12$ years & $2.61 \pm 0.91$ & $1.72 \pm 0.86$ & $2.14 \pm 1.45$ & $2.04 \pm 1.55$ \\
\hline Above 12 years & $2.85 \pm 0.93$ & $1.77 \pm 0.79$ & $2.02 \pm 1.47$ & $1.91 \pm 1.54$ \\
\hline \multicolumn{5}{|l|}{ Influence of media } \\
\hline \multicolumn{5}{|l|}{ Exposure to television } \\
\hline Yes & $2.91 \pm 0.92^{* *}$ & $1.75 \pm 0.92$ & $2.23 \pm 1.50^{* *}$ & $1.77 \pm 1.52^{* *}$ \\
\hline
\end{tabular}

${ }^{*}$ Significant at 0.05 level; ${ }^{* *}$ significant at 0.01 level.

have close associations with body weight consciousness and weight related behaviours of the study participants (Table 3 ).

The study reveals that religion, economic status, level of parental education, and media influence are shown to have close associations with body weight consciousness and weight related behaviours of the study participants (Table 3 ).

\section{Discussion}

Driven by the feeling of dissatisfaction over body image, adolescents practice dietary modifications and/or dieting, which usually refer to changes in the food preferences and amount of consumption and also can help increase or decrease body fat [21]. Following the consciousness of being overweight, these girls tend to avoid certain food items, restrict calories (by not having calorie rich foods) and follow dieting which generally involve either skipping meals or adopting certain unhealthy means to reduce body weight.

Significant difference in consciousness over calorie consumption is noticed with respect to religion, family size, father's level of education, and the level of exposure to television. In case of avoidance of certain foods significant difference is observed with respect to their age and father's education and occupation indicating this to be a phenomenon of higher economic status. A significant difference in dieting behaviour is noticed with respect to age, religion, level of father's occupation, and education of both the parents along with exposure to television. Results of the present study are consistent with the trends reported in several studies across the globe $[1,22]$. 
TABLE 3: Results of stepwise multiple regression analysis using sociodemographic variables as predictors of different issues related to dietary practices.

\begin{tabular}{|c|c|c|c|}
\hline Dependent variable & Significant predictor(s) & $\beta$-coefficient & $R^{2}$ \\
\hline \multirow{3}{*}{ Dieting } & Religion & 0.12 & \multirow{3}{*}{0.07} \\
\hline & Age of participant & 0.17 & \\
\hline & Father's occupation & 0.14 & \\
\hline Food avoidance & Mother's occupation & -0.13 & 0.02 \\
\hline Consciousness about calorie consumption & Father's occupation & 0.15 & 0.02 \\
\hline \multirow{2}{*}{ Concern for being overweight } & Father's level of education & 0.18 & \multirow{2}{*}{0.09} \\
\hline & Religion & 0.17 & \\
\hline
\end{tabular}

The study reveals that religion, economic status, level of parental education, and media influence are shown to have close associations with body weight consciousness and weight related behaviours of the study participants. Religion and media habits are found to be two most important factors affecting almost all weight related behaviours considered in this study. Field et al. [16] have criticized media for promoting disordered eating habits among females. Confirming the trend, the present study revealed that media habits (in terms of watching television) played a significant role in developing consciousness about body weight which also occupies an important place in the life of these adolescent girls. Association between study participants' age and dieting indicates that dissatisfaction with body weight and weight control practices among adolescents develops with advancement of age. The results are consistent with the findings of other studies [23, 24].

The major limitation of the study is no anthropometric measures (like height and weight) were considered to ascertain obesity status of the study participants. In case of information on viewing television, exposure of hours per week could not be recorded; hence, the data has been interpreted as influence of media instead of exposure to media.

\section{Conclusion}

The present microlevel study involves two groups of adolescent girls, Hindu and Muslim, and discussed their behaviours related to controlling their body weight, an issue not so common in India particularly in West Bengal. The study documents that concern over body image and weight loss is important among girls of these two religious groups. It can be suggested that parents, media, and educational institutions have to play crucial roles to prevent them from developing unhealthy weight control behaviours.

\section{Conflict of Interests}

The authors declare that there is no conflict of interests regarding the publication of this paper.

\section{Acknowledgments}

The authors are most thankful to the study participants for their unhesitant support to complete the study. The financial support provided by the Indian Statistical Institute is gratefully acknowledged.

\section{References}

[1] D. Neumark-Sztainer, M. E. Eisenberg, J. A. Fulkerson, M. Story, and N. I. Larson, "Family meals and disordered eating in adolescents," Archives of Pediatrics and Adolescent Medicine, vol. 162 , no. 1, pp. 17-22, 2008.

[2] S. K. Mishra and S. Mukhopadhyay, "Eating and weight concerns among Sikkimese adolescent girls and their biocultural correlates: an exploratory study," Public Health Nutrition, vol. 14 , no. 5, pp. 853-859, 2011.

[3] A. K. Kant, "Dietary patterns and health outcomes," Journal of the American Dietetic Association, vol. 104, no. 4, pp. 615-635, 2004.

[4] L. K. Bachrach, D. Guido, D. Katzman, I. F. Litt, and R. Marcus, "Decreased bone density in adolescent girls with anorexia nervosa," Pediatrics, vol. 86, no. 3, pp. 440-447, 1990.

[5] Position Paper for the Society for Adolescent Medicine, "Eating disorders in adolescents," Journal of Adolescent Health, vol. 33, pp. 496-503, 2003.

[6] S. A. French and R. W. Jeffery, "Consequences of dieting to lose weight: effects on physical and mental health," Health Psychology, vol. 13, no. 3, pp. 195-212, 1994.

[7] E. H. Wertheim, S. J. Paxton, H. K. Schutz, and S. L. Muir, "Why do adolescent girls watch their weight? An interview study examining sociocultural pressures to be thin," Journal of Psychosomatic Research, vol. 42, no. 4, pp. 345-355, 1997.

[8] E. A. Schur, M. Sanders, and H. Steiner, "Body dissatisfaction and dieting in young children," International Journal of Eating Disorders, vol. 27, pp. 74-82, 2000.

[9] D. Neumark-Sztainer, R. W. Jeffery, and S. A. French, "Selfreported dieting: how should we ask? What does it mean? Associations between dieting and reported energy intake," International Journal of Eating Disorders, vol. 22, pp. 437-449, 1997.

[10] M. Story, K. Rosenwinkel, J. H. Himes, M. Resnick, L. J. Harris, and R. W. Blum, "Demographic and risk factors associated with chronic dieting in adolescents," The American Journal of Diseases of Children, vol. 145, no. 9, pp. 994-998, 1991.

[11] M. Grigg, J. Bowman, and S. Redman, "Disordered eating and unhealthy weight reduction practices among adolescent females," Preventive Medicine, vol. 25, no. 6, pp. 748-756, 1996.

[12] J. Croll, D. Neumark-Sztainer, M. Story, and M. Ireland, "Prevalence and risk and protective factors related to disordered eating behaviors among adolescents: relationship to gender and ethnicity," Journal of Adolescent Health, vol. 31, no. 2, pp. 166$175,2002$. 
[13] D. Neumark-Sztainer, M. Story, N. H. Falkner, T. Beuhring, and M. D. Resnick, "Sociodemographic and personal characteristics of adolescents engaged in weight loss and weight/muscle gain behaviors: who is doing what?" Preventive Medicine, vol. 28, no. 1, pp. 40-50, 1999.

[14] R. Chugh and S. Puri, "Affluent adolescent girls of Delhi: eating and weight concerns," British Journal of Nutrition, vol. 86, no. 4, pp. 535-542, 2001.

[15] B. Sadana, M. Khanna, and S. K. Mann, "Consumption patterns of fast foods among teenagers," Applied Nutrition, vol. 22, pp. 14-17, 1997.

[16] A. E. Field, S. B. Austin, R. Striegel-Moore et al., "Weight concerns and weight control behaviors of adolescents and their mothers," Archives of Pediatrics and Adolescent Medicine, vol. 159, no. 12, pp. 1121-1126, 2005.

[17] R. C. Plotnikoff, K. Bercovitz, R. E. Rhodes, C. A. Loucaides, and N. Karunamuni, "Testing a conceptual model related to weight perceptions, physical activity and smoking in adolescents," Health Education Research, vol. 22, no. 2, pp. 192-202, 2007.

[18] Census of India, Provisional Population Total of Howrah District, Census of India, New Delhi, India, 2001.

[19] West Bengal Madrasah Board, http://www.wbbme.org/.

[20] D. M. Garner and P. E. Garfinkel, “The eating attitudes test: an index of the symptoms of anorexia nervosa," Psychological Medicine, vol. 10, no. 2, pp. 647-656, 1979.

[21] G. Rodríguez and L. A. Moreno, "Is dietary intake able to explain differences in body fatness in children and adolescents?" Nutrition, Metabolism and Cardiovascular Diseases, vol. 16, no. 4, pp. 294-301, 2006.

[22] T. Y. Mousa, H. A. Al-Domi, R. H. Mashal, and M. A. Jibril, "Eating disturbances among adolescent schoolgirls in Jordan," Appetite, vol. 54, no. 1, pp. 196-201, 2010.

[23] M. Marchi and P. Cohen, "Early childhood eating behaviors and adolescent eating disorders," Journal of the American Academy of Child and Adolescent Psychiatry, vol. 29, no. 1, pp. 112-117, 1990.

[24] S. G. Gowers and A. Shore, "Development of weight and shape concerns in the aetiology of eating disorders," British Journal of Psychiatry, vol. 179, pp. 236-242, 2001. 

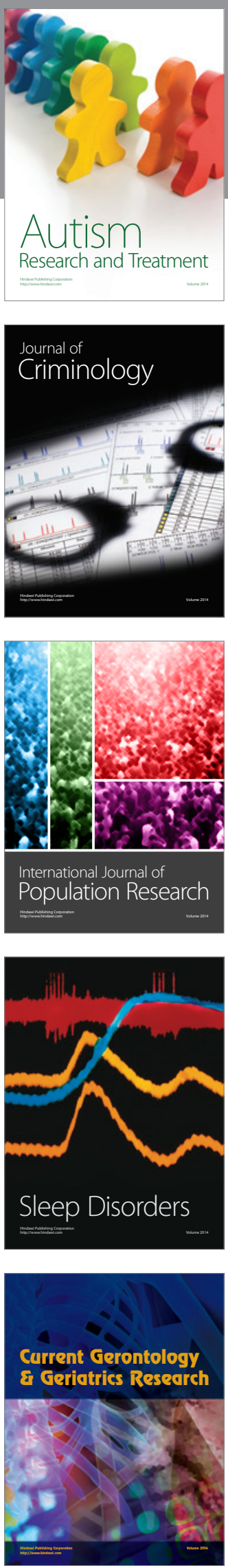
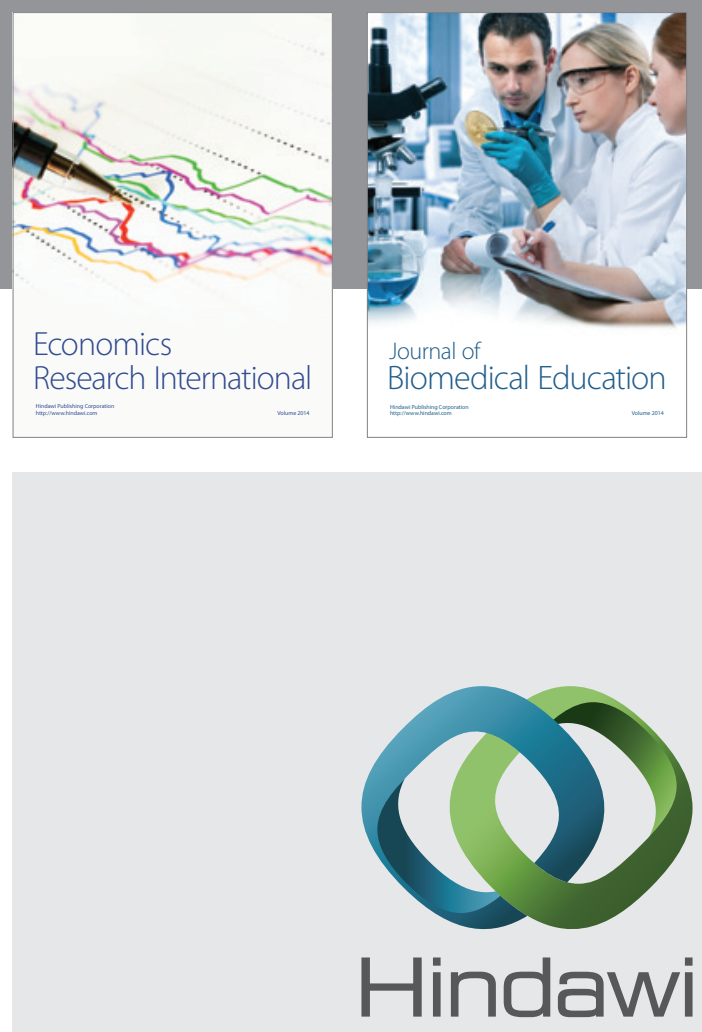

Submit your manuscripts at

http://www.hindawi.com
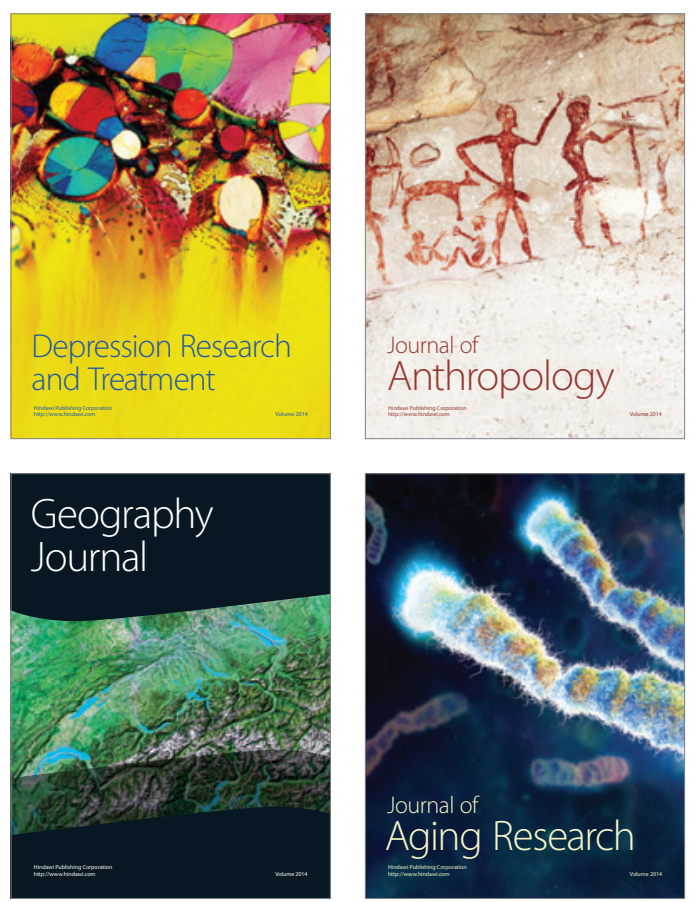
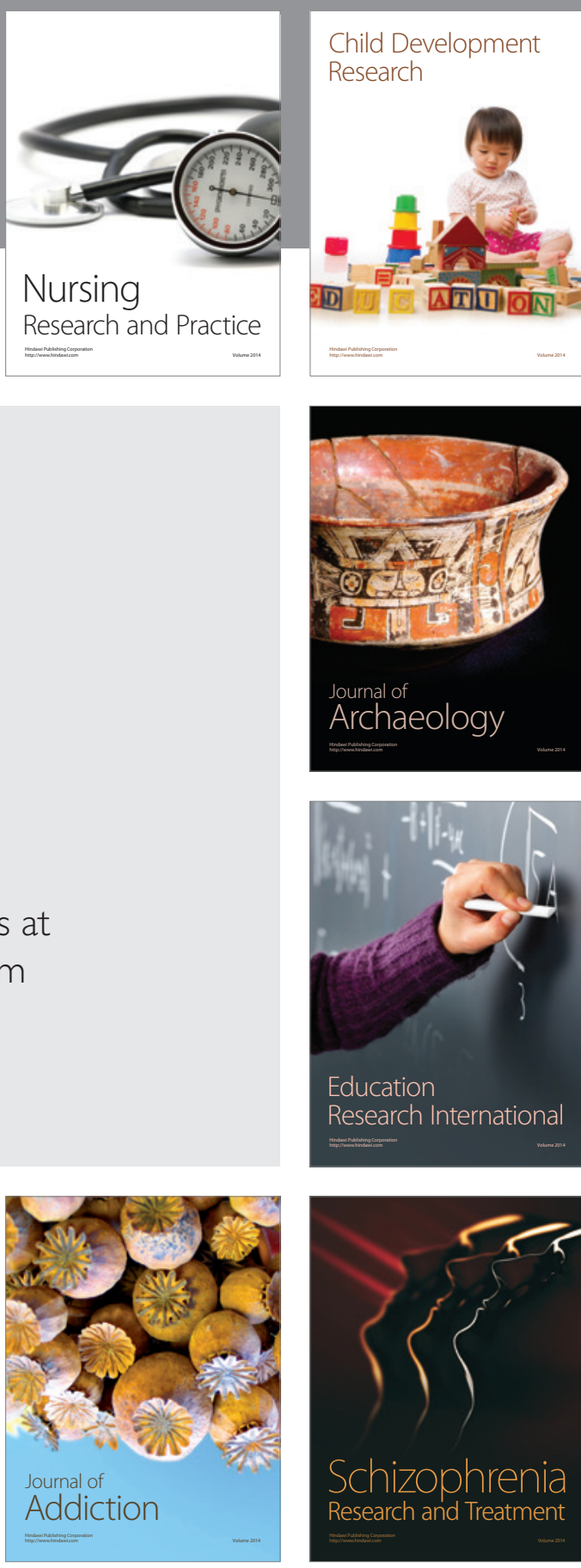

(D)
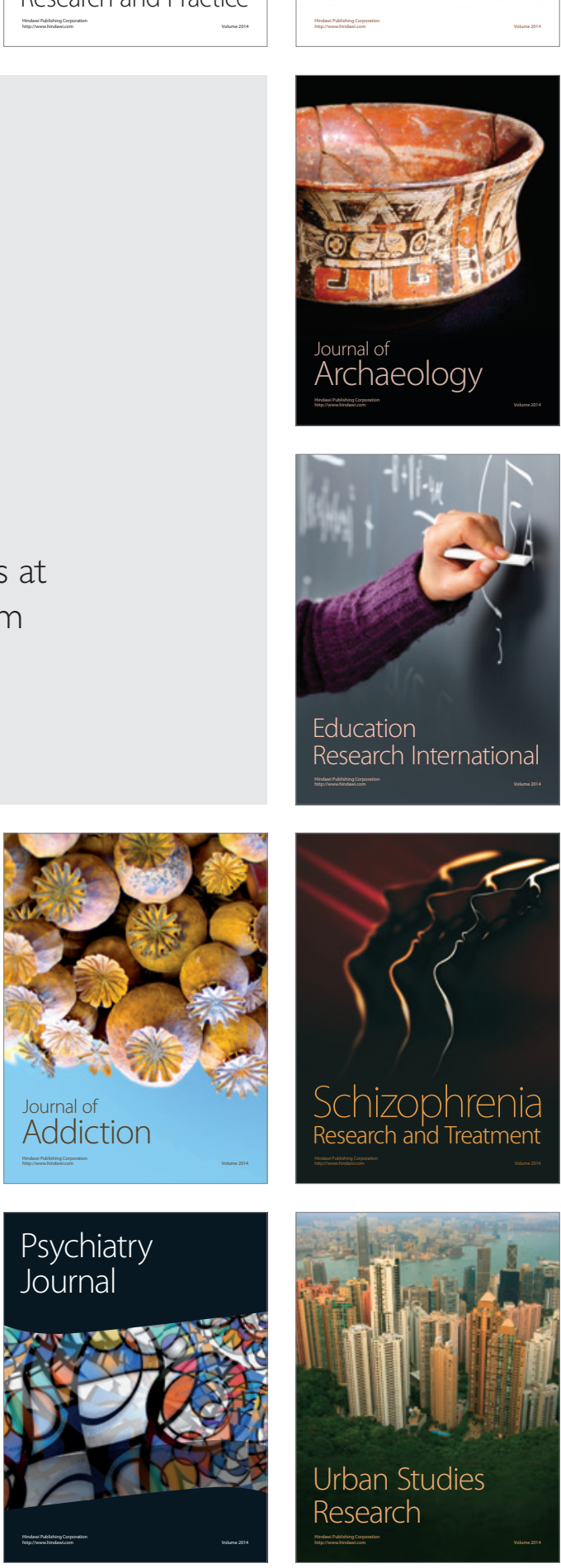